\title{
Numerical Investigation of the Trailing Edge Shape on the Added Damping of a Kaplan Turbine Runner
}

\author{
Zhang Ming, P. A. Mbango-Ngoma, Du Xiao-zhen, and Chen Qing-Guang $\mathbb{D}$ \\ College of Mechanical and Electronic Engineering, Shandong University of Science and Technology, Qingdao, \\ Shandong 266590, China \\ Correspondence should be addressed to Chen Qing-Guang; chenqg@sdust.edu.cn
}

Received 22 June 2021; Revised 11 July 2021; Accepted 27 July 2021; Published 4 August 2021

Academic Editor: Jie Chen

Copyright (c) 2021 Zhang Ming et al. This is an open access article distributed under the Creative Commons Attribution License, which permits unrestricted use, distribution, and reproduction in any medium, provided the original work is properly cited.

Hydraulic turbine runners experience high excitation forces in their daily operations, and these excitations may cause resonances to runners, which may induce high vibrations and shorten the runner's lifetimes. Increasing the added damping of runners in water can be helpful to reduce the vibration level during resonances. Some studies have shown that the modification of the trailing edge shape can be helpful to increase added damping of hydrofoils in water. However, the influence of blade trailing edge shape on the added damping of hydraulic turbine runners has been studied in a limited way before. Due to the difficulties to study this problem experimentally, the influence of blade trailing edge shape on a Kaplan turbine runner has been studied numerically in this paper and the one-way FSI method was implemented. The performances of three different turbulence models, including the $k-\epsilon$, $k-\omega$ SST, and transition SST models, in the added damping simulation of the NACA 0009 hydrofoil were evaluated by comparing with the available results of the two-way FSI simulation in the references. Results show that, unlike the significantly different performances in the two-way FSI method, the performances of all the turbulence models are very close in the one-way FSI method. Then, the $k-\epsilon$ turbulence model was applied to the added damping simulation of a Kaplan turbine runner, and results show that the modification of the blade trailing edge shape can be helpful to increase the added damping to some extent.

\section{Introduction}

Nowadays, hydropower plays an important role in world electricity generation, and over $21 \%$ percent of world electricity is produced by hydropower every year [1]. Due to the fast increase of wind and solar energy for electricity generation in recent years, great unstableness is introduced to the electricity grid. Hydropower can provide fast responses for the power regulation to adjust the unstableness of the electricity grid caused by some other renewable sources, like solar and wind energy [1], and its load can change from $20 \%$ to $100 \%$ in less than 1 minute. Therefore, hydraulic turbines operate at extreme off-design conditions and experience transient events much more times one day than before, which leads to even larger forces. Such higher forces can produce higher vibration levels in the runners, which can cause fatigue damage and shorten their lifetime. Such failures are attributed to the fluid-structure interaction
(FSI) caused by the rotor-stator interaction (RSI) [2-5]. Sometimes, the runner's natural frequency is very much close to the frequency of RSI and/or its harmonic and causes resonances to the runner. This amplifies the amplitudes of runner vibrations and greatly accelerates its fatigue progress [6-8].

Kaplan turbines are one type of widely used hydraulic turbines that are mostly used in low water head and large capacity hydropower plants [9], and the blades of Kaplan turbine runners can rotate to make the runner operate under high efficiencies for a wide range of operation. The typical structure of Kaplan turbines is shown in Figure 1. The excitation forces of Kaplan turbine runners can be both static and dynamic pressures [10-15]. The dynamic pressure mostly comes from the rotor-stator interaction (RSI). Due to the aforementioned reasons, several failure cases for Kaplan turbine runners have been reported in the literature, and some are caused by resonances $[6,16-18]$. 


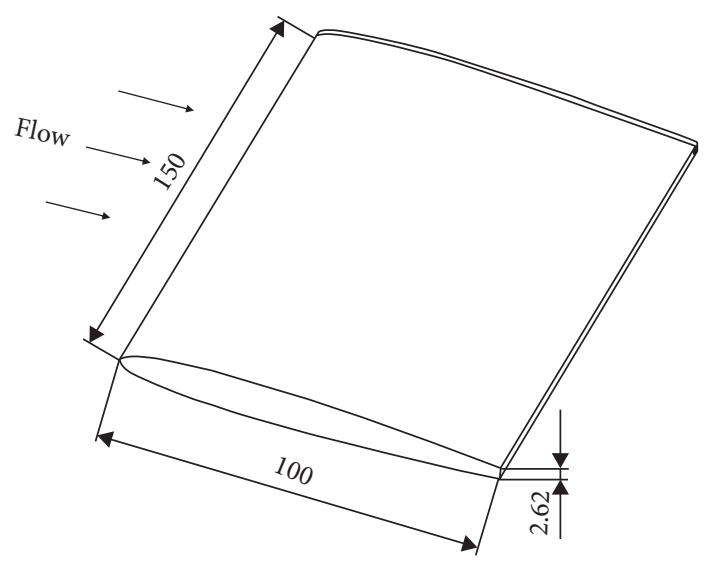

Figure 1: Blunt trailing edge hydrofoil.

To reduce the vibration levels of Kaplan turbine runners during resonances to increase their lifetimes, increasing their damping ratios can be helpful. Kaplan turbine runners are submerged in water in daily operations, and their dynamic behavior is severely affected by the added mass and added damping effect from the surrounding water [19-21]. To increase the damping of Kaplan turbine runners, increasing the added damping in water can be a practical way. A good review on the added damping in hydraulic turbines has been shown in [20], where a measure to increase the added damping by modifying the trailing edge shape of the blades has been mentioned. Blake first found that the vibration amplitude of Francis turbine runners can be greatly reduced by sharpening the trailing edge of blades, particularly the Donaldson trailing edge, which has a smooth transition for the sharpening [22]. To study the mechanism of how Donaldson trailing edge reduced the vibration amplitude, Zobeiri investigated the influence of trailing edge shapes, including the blunt trailing edge and the Donaldson trailing edge, on the wake dynamics of a NACA 0009 hydrofoil, and they found that the Donaldson trailing edge can reduce the distance between the vortices after the trailing edge compared with that of blunt trailing edge and increase their collision, which increases the energy dissipation [23]. Yao Yao et al. understand the effect of trailing edge shape from the viewpoint of added damping, and they found that the Donaldson trailing edge can significantly increase the added damping of the NACA 0009 hydrofoil, which explains why the Donaldson trailing edge can be helpful to reduce the vibration level $[24,25]$. However, there are no studies on the influence of blade trailing edge shape on the added damping of real hydraulic turbine runners, particularly Kaplan turbine runners.

To measure the added damping of hydraulic turbine runners is very difficult because runners are enclosed by case walls and submerged in water, which makes the sensor installations and data transmissions very difficult. Therefore, investigating the added damping based on numerical methods probably can be an ideal way. The numerical methods for the added damping simulation can be divided into two types, one is the one-way fluid-structure interaction (FSI) method, and another one is the two-way fluid- structure method. The two-way FSI method needs to give the structure an initial excitation and then measure the vibration amplitude decay ratio to extract the damping ratio. Generally, the two-way FSI method is more theoretical integrity, but the calculation cost is usually very high. Zeng et al. used the two-way FSI method to investigate the influence of trailing edge shape on the added damping of the NACA 0009 hydrofoil, and the results fitted the experimental results very well $[25,26]$. In their investigations, they also investigated the influence of turbulence models on the results, including the $k-\epsilon, k-\omega S S T$, and transition SST models, and they found that the transition SST model can accurately capture the velocity and pressure distributions in the boundary layer, thus accurate damping compared with experimental results. However, the $k-\epsilon$ model and $k-\omega$ SST model can produce large errors.

The one-way FSI method needs to project the mode shape to the structure boundary and then integrate the flow field parameters under the periodic vibration of the structure boundary. Generally, the one-way FSI method is not theoretical integrity, as the influence of mode shape change due to the fluid flowing is not considered. However, for submerged structures, the mode shape change due to the water flowing usually is not significant, together with considering the much less calculation cost compared with the two-way FSI method, the one-way FSI method is also used by many researchers, and good results were obtained compared with experimental results. Tengs et al. use the one-way fluidstructure method based on the $k-\omega$ SST turbulence model to investigate the added damping of a hydrofoil in flowing water, and little errors were found between the numerical and experimental results [27]. Gauthier et al. developed an improved one-way fluid-structure method with the consideration of the added stiffness and added mass change due to the water flowing and applied this method to investigate the added damping of a hydrofoil and a Kaplan turbine runner [28]. In their study, the $k-\epsilon$ turbulence model was used, and limited errors were found compared with the experimental results.

Due to the too high computation cost of the two-way FSI method, in this study, the one-way FSI method in [28] will be used to investigate the influence of the blade trailing edge shape on the added damping of a Kaplan turbine runner. One problem with the one-way FSI method is the influence of the turbulence model used on the results. Though different turbulence models can produce significant differences in the final results for the two-way FSI method, when different researchers used different turbulence models to do the one-way FSI simulation to simulate the added damping, they all claimed that good results were obtained. Therefore, some uncertainties still lie in the performances of different turbulence models when using the one-way FSI method. To know the performance differences of different turbulence models is important for accurate simulation result achievements. In this study, firstly, the performances of three turbulence models, including the $k-\epsilon, k-\omega S S T$, and transition SST models, will be evaluated when they are used in the one-way FSI method for the influence of the trailing edge shape on the added damping of a NACA 0009 hydrofoil 
in [25], and then, the turbulence model with the best performance will be applied for the influence of blade trailing edge shape on the added damping of a Kaplan turbine runner.

\section{Numerical Methods}

The one-way FSI method developed in [28] will be used in this paper. Due to the little influence of damping on the natural frequencies, by neglecting the structure damping, the motion of one vibrating system is described by

$$
M_{S} \ddot{x}+K_{S}=F_{F}(t) \text {. }
$$

The natural frequency in vacuum $\omega_{v}$ of the system motion described by equation (1) depending only on structure parameters is

$$
\omega_{v}^{2}=\frac{K_{S}}{M_{S}}
$$

$M_{S}$ represents the structure modal mass and $K_{S}$ the structure modal stiffness, where $F_{F}(t)$ represents the fluid total modal force applied on the structure and $x$ is representing the deflection.

The structure modal mass and the total force introducing the chosen mode shape are expressed as

$$
M_{S}=\iiint_{\Omega} \rho_{S} \varphi^{2} \mathrm{~d} V, F_{F}(t)=\iint_{\Gamma} \tau(t) \cdot \varphi \mathrm{d} S .
$$

$\rho_{S}$ represents the structure density, $\Omega$ represents the structure volume, and the total surface load induced on the structure by the flow and the fluid-structure interface are, respectively, represented by $\tau$ and $\Gamma$.

Considering the effect of added mass and added stiffness, the natural frequency, $\omega_{n}$, of the system becomes

$$
\omega_{n}^{2}=\frac{K_{s}+K_{F}}{M_{s}+M_{F}} .
$$

The dimensionless damping ratio is then represented as

$$
\zeta=\frac{C_{F}}{2 \omega_{n}\left(M_{s}+M_{F}\right)} .
$$

$M_{F}$ represents the fluid-added mass, $C_{F}$ is the fluidadded modal damping coefficient, and $K_{F}$ is the fluidadded modal stiffness. The added mass can be interpreted as the mass of fluid accelerated due to the motion of the structure. The added stiffness describes the change in the flow-induced restoring force with the deflection of the structure. The added damping represents energy extracted from the structure as a result of work done by the fluid flow.

Three types of simulations need to be done in order to obtain the above parameters: modal analysis, steady-state CFD analysis, and unsteady CFD analysis. For one selected mode, the modal analysis is mainly used to get the natural frequency, modal mass, and stiffness in vacuum and water. The wet natural frequency and mode shape will act as the initial values for the following simulation. The steady-state CFD is mainly used to get the added stiffness in water, and the transient CFD is mainly used to update the added mass and calculate the added damping in water.

2.1. Modal Analysis in Vacuum and Water. A modal analysis in vacuum provides the initial circular natural frequency $\omega_{v}$. The mode shape in vacuum can be extracted, and the modal mass $M_{S}$ can be calculated from equation (2) or exported from the FEM software directly. The modal stiffness $K_{S}$ can be calculated from equation (2). Then, the wet modal analysis of the structure in water will be done, which can be achieved through the Acoustic FSI technology available in Ansys. The wet modal analysis will provide the frequency $\omega_{f}$ and mode shape in still water used in the following simulation. The added mass $M_{F}$ in still water can be calculated from the following equation:

$$
\omega_{f}=\frac{1}{2 \pi} \sqrt{\frac{K_{S}}{M_{S}+M_{F}}} .
$$

2.2. Steady-State CFD. For the steady state, the modal force can be written as a sum of two forces:

$$
F_{F}=F_{0}-K_{F} x
$$

The fluid-added stiffness, $K_{F}$, corresponds to a gradient, defined by the variation of the modal total force over the variation of the deflection $-\mathrm{d} F_{F} / \mathrm{d} x$. So, at least two values of both the modal total force and the structure deflection are needed. For linearity purposes, the difference between deflection values has to be very small. URANS flow simulations of five deflection values of the structure were done to get the fluid-added stiffness.

2.3. Transient CFD Analysis. The harmonic modal motion of the structure is defined as

$$
x(t)=X_{0} \sin \left(\omega_{n} t\right) .
$$

By projecting the motion to the flow field, a transient CFD simulation can be done. An averaged quantity, $\Phi$, can be calculated as

$$
\phi=\frac{1}{N} \int_{t_{0}}^{t_{0}+\left(2 \pi N / \omega_{n}\right)} F_{F} \cdot x(t) \mathrm{d} t,
$$

where $\mathrm{N}$ is an integer number of oscillations and $t_{0}$ an arbitrary time coordinate. If the number of periods is high enough, substituting equation (4) into equation (8) results in

$$
\phi=\pi X_{0}^{2} \omega_{n} M_{F} \text {. }
$$

From equations (8) and (9), the natural frequency can be updated and used in the following transient CFD simulation. With some repetition, the convergent added mass can be obtained. The average modal work done by the flow on the structure, $W$, can be obtained as 


$$
W=\frac{1}{N} \int_{t_{0}}^{t_{0}+\left(2 \pi N / \omega_{n}\right)} F_{F} \cdot \dot{x} \mathrm{~d} t
$$

If the number of oscillations is high enough, $W$ goes to its convergent value:

$$
W=-C_{F} \pi X_{0}^{2} \omega_{n}
$$

From equations (11) and (12), $C_{F}$ can be obtained for the added damping ratio calculation in equation (4).

\section{Results and Discussion}

\subsection{Hydrofoil}

3.1.1. Physical Model. The simulated hydrofoil is the 3D NACA 0009 hydrofoil used in [24-26], and in their research, the influence of the trailing edge shape on the added damping was studied. Blunt trailing edge hydrofoil is presented by Figure 1 with a chord length $L=100 \mathrm{~mm}$, the width of the span is $w=150 \mathrm{~mm}$, and the trailing edge thickness is $h=3.22 \mathrm{~mm}$. The hydrofoil of structural steel material has a density of $\rho_{S}=7700 \mathrm{~kg} / \mathrm{m}^{3}$, the elasticity modulus is $E=215 \mathrm{GPa}$, and Poisson's ratio is $v=0.3$. The angle of attack of the hydrofoil in the calculation domain is $0^{\circ}$. The configurations of the calculation domain are shown in Figure 2.

The Donaldson trailing edge hydrofoil is a modification of the blunt model. Figure 3 presents the operations to modify the trailing edge from the blunt one to the Donaldson one. Several parameters have to be taken into account as the angle $\alpha=45^{\circ}$, the oblique tangent $l_{1}$, and the cubic polynomial curve $l_{2}$. The cubic polynomial is expressed by

$$
\left\{\begin{array}{l}
y=\mathrm{ax}^{3}+\mathrm{bx}^{2}+\mathrm{cx}+d \\
a=2595.18, b=637.51, c=51.141, d=1.322
\end{array}\right.
$$

3.1.2. Modal Analysis in Vacuum and Water. The modal analysis was done through Ansys Workbench 19.2. Fix support was given to the end of the hydrofoil. For the modal analysis in water, Acoustic FSI technology was used to simulate the added mass effect from the surrounding water, which is a reliable simulation technology used by many researchers $[29,30]$. The water domain was selected as the acoustic body with a density of $1000 \mathrm{~kg} / \mathrm{m}^{3}$ and a sound speed of $1483 \mathrm{~m} / \mathrm{s}$. The inlet and outlet were set to be the total absorption surface, and all other walls were set to be rigid walls. A fluid-structure coupled algorithm was implemented. The mode shape and natural frequency of the first bending mode in water were set as the initial frequency and mode shape for the following CFD analysis. When the hydrofoil is submerged in water, common nodes technology was used for the mesh at the fluid-structure interfaces. The view of the mesh for the hydrofoil in vacuum is shown in Figure 4. The mode shapes of the first bending mode of the blunt and Donaldson hydrofoil in water are shown in Figure 5. The modal parameters are shown in Table 1.
3.1.3. Steady CFD Analysis. The boundary conditions for the CFD analysis are shown in Figure 2. A velocity inlet was used with a low turbulence intensity of $1 \%$, and three different inlet velocities were tested. The outlet boundary is defined as a pressure outlet with a $0 \mathrm{~Pa}$ relative pressure. The up, down, left, and right sides are all set as walls. The mode shape profile of the first bending mode was projected to the hydrofoil surface, and in the steady CFD analysis, the hydrofoil was set as the wall with different specific displacements (from $0.01 \mathrm{~mm}$ to $0.05 \mathrm{~mm}$ ). Three different turbulence models, including the $k-\epsilon, k-\omega \mathrm{SST}$, and transition SST models, were tested, and for each turbulence model, the modal forces under different hydrofoil displacements were interacted over the hydrofoil surface to calculate the added stiffness. The mesh sensitivity has been strictly checked, and the view of the mesh of the blunt hydrofoil has been shown in Figure 6. The thickness of the first layer of the boundary layers is about $0.001 \mathrm{~mm}$, which corresponds to a $y+$ about 1 when the inlet velocity is $15 \mathrm{~m} / \mathrm{s}$. For the $k-\epsilon$ turbulence model, scalable wall functions were implemented. A backward Euler second-order time integration scheme was implemented in the analysis. The modal force change versus the hydrofoil displacement under the inlet velocity of $10 \mathrm{~m} / \mathrm{s}$ has been shown in Figure 7. The modal force nearly linearly increases with the deflection amplitude, and the gradient of the fit curve, that is to say, the added stiffness, is about 0.47 . Therefore, the added stiffness is very small compared with the structural stiffness (see in Table 1), and this is maybe because the hydrofoil is symmetric and because of the 0 degree incidence angle of the flow. Due to the small influence of the added stiffness, it is directly neglected for the added damping calculation for all the cases of the hydrofoil.

3.1.4. Transient CFD Analysis. For transient CFD analysis, the mode shape profile of the first bending mode was projected to the hydrofoil surface, and the hydrofoil was set as the wall with periodic displacement with an amplitude of $0.05 \mathrm{~mm}$. The initial frequency is the natural frequency of each hydrofoil in still water. Totally 15 periods of vibration cycles were calculated for each case, and the last 10 periods were used to calculate the added mass and added damping to avoid the influence of the initial turbulence. For each vibration period, 400 substeps were used which has been shown enough for this type of structure [28]. A doubleprecision solver was selected for calculation via a 64-core cloud computer.

The modal forces along with the time steps (2000 to 4000 ) for the blunt hydrofoil under the inlet velocity of $5 \mathrm{~m} /$ $\mathrm{s}, 10 \mathrm{~m} / \mathrm{s}, 15 \mathrm{~m} / \mathrm{s}$ when the turbulence model is transition SST have been shown in Figure 8, and the modal forces along with the time steps (2000 to 4000) for the blunt hydrofoil using three different turbulence models under the inlet velocity of $10 \mathrm{~m} / \mathrm{s}$ have been shown in Figure 9 . When the inlet velocity becomes higher, the modal force curve may become not that smooth which may be because the turbulence intensity becomes higher.

The frequency updating of the Donaldson hydrofoil under the inlet velocity of $10 \mathrm{~m} / \mathrm{s}$ when using the $k-\omega$ SST 


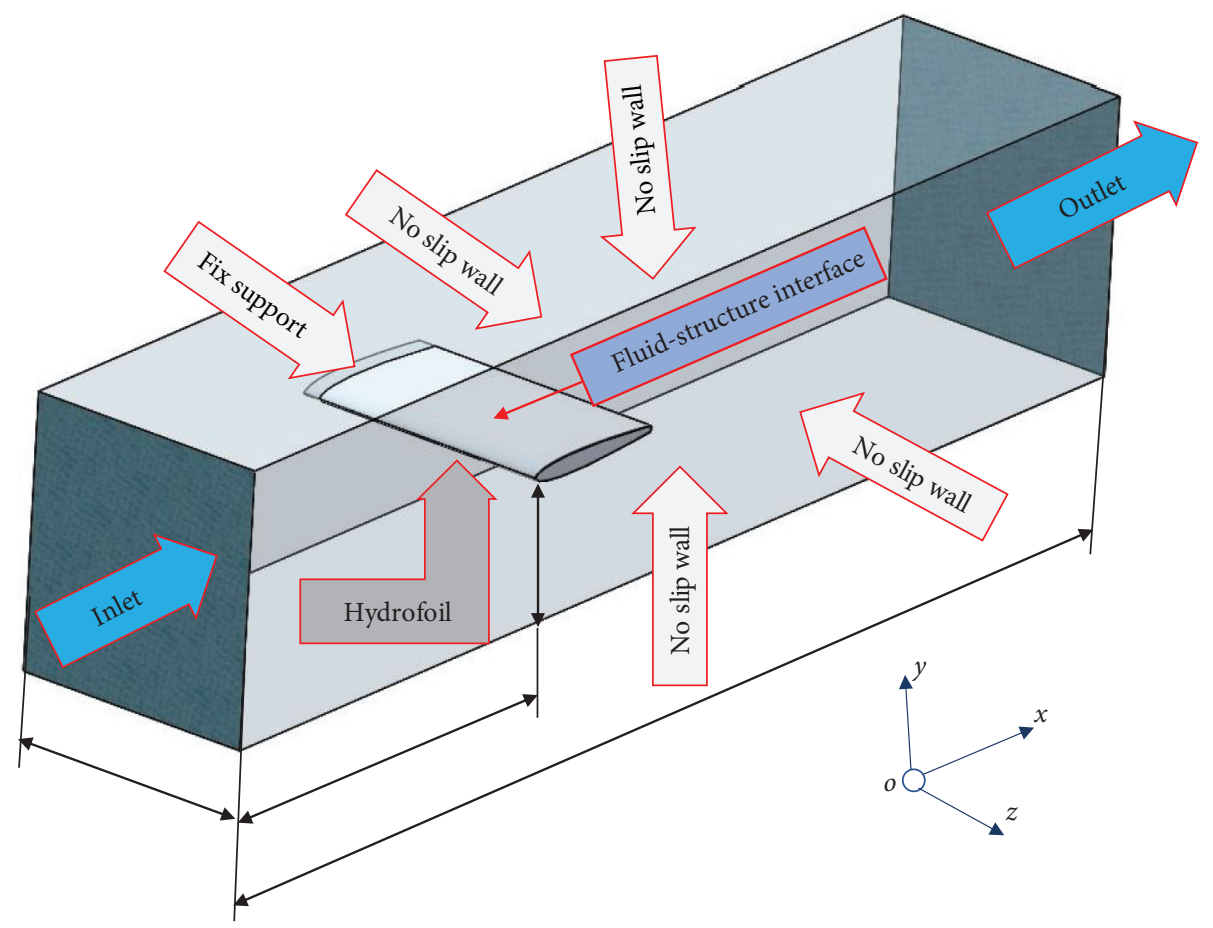

Figure 2: Calculation domain configurations of the hydrofoil.
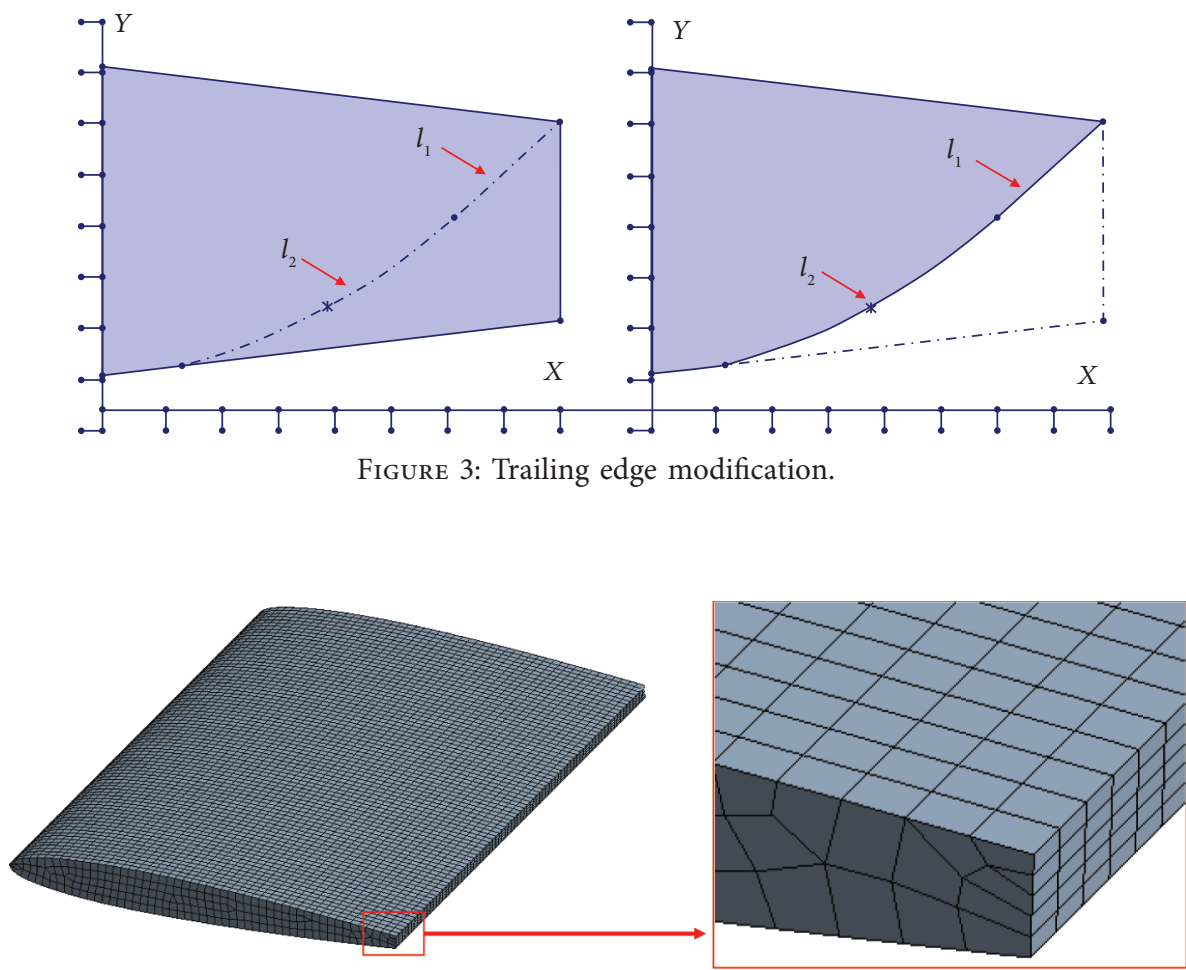

FIGURE 4: Blunt trailing edge hydrofoil mesh.

model has been shown in Table 2. After two steps of updating, the frequency has been nearly convergent. Therefore, two steps of updating were applied to all the simulation cases.
The results obtained from the two-way FSI simulation by [25] are also shown in the figure. As can be seen, the results obtained from different turbulence models are very close for both the blunt and Donaldson hydrofoils, and the results are 


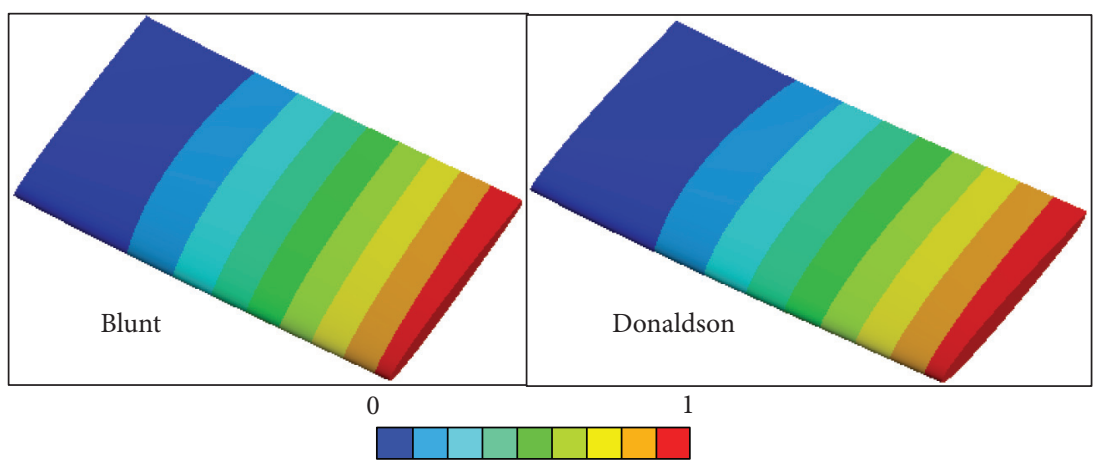

Figure 5: Bending mode shapes of the blunt and Donaldson hydrofoil.

TABle 1: Modal parameter for the bending mode of the blunt and Donaldson hydrofoils.

\begin{tabular}{lcccc}
\hline & $f_{v}(\mathrm{~Hz})$ & $f_{w}(\mathrm{~Hz})$ & $M_{F} / M_{S}$ & $K_{S}(\mathrm{~N} / \mathrm{m})$ \\
\hline Blunt & 283.26 & 188.44 & 2.2596 & 5076.3 \\
Donaldson & 284.38 & 189.94 & 2.2416 & 5157.4 \\
\hline
\end{tabular}

also very close to the results obtained from the two-way FSI simulation. This on the one hand confirms our simulation configurations, and on the other hand, unlike the influence of the turbulence model on the results of the two-way FSI method, the turbulence model seems to affect the results of the one-way FSI method very little. This can also be seen in Figure 7 that the modal forces of the three turbulence models are nearly the same, and thus, nearly the same results are obtained.

\subsection{Kaplan Turbine Runner}

3.2.1. Physical Model. The investigated turbine is the same one described in $[30,31]$. The turbine has a head of $34 \mathrm{~m}$ and a maximum power of $73 \mathrm{MW}$. The runner has 6 blades rotating at $125 \mathrm{rpm}$, and the distributor has 24 guide vanes. The flow rate at the best efficiency point is about $22.5 \mathrm{~m}^{3} / \mathrm{s}$. The diameter of the runner is about $6 \mathrm{~m}$, and the tip clearance is $0.09 \%$ of the outlet diameter of the runner. The geometry sketch of the studied Kaplan turbine is shown in Figure 11.

Due to the geometry complexity of the blades, it is impossible to sharpen the blade trailing edge with a curve that has an accurate equation as that on the hydrofoil. In this paper, the blade trailing edge was given a proximate 45degree sharpener with smooth transitions. The geometry view of the blunt and Donaldson blade has been shown in Figure 12.

To purely investigate the influence of the trailing edge shape on the added damping of the runner, only six blades submerged in the water domain were simulated. The blade model has been validated in another paper by the author [30]. For simple, an isolated stage without considering the stay vanes was investigated, and the water domain from the end of the stay vanes to the bottom of the hub was considered. The blade angle of the runner at the nominal load was studied. Only the bending mode of 0 nodal diameters, i.e., mode for which the motion of every blade is in phase, was considered in the simulation. Due to the low added stiffness of this type of structure [28], the steady CFD analysis was eliminated, and the influence of the added stiffness was neglected.

3.2.2. Modal Analysis. For the modal analysis in vacuum, only one blade was simulated. The blade material is stainless steel. The surface where the rod connects the blade profile was fixed. For the wet modal analysis in water, all the blades were simulated together, and the surrounding water was selected as the acoustic body. The surfaces at which the simulated blades connect with the water domain wer set to be fluid-structure interfaces, the inlet and outlet surface were set to be totally absorbed surfaces (the absorption coefficient is 1), and all other surfaces were set to be rigid walls. Only the bending mode was considered. Due to the little mode shape changes from vacuum to water, the blade mode shape in vacuum was used for the following CFD analysis. The view of the mesh in water is shown in Figure 13. The bending mode shapes of the blunt and Donaldson blades have been shown in Figure 14. The natural frequencies of the 0 ND bending modes of the blunt and Donaldson blades in water were selected as their initial frequencies in the following CFD analysis.

3.2.3. Transient CFD Analysis. For the transient CFD analysis, the amplitude of the blade vibration was set to be $0.0005 \mathrm{~m}$, which was also used in [28]. Because the turbulence model has been demonstrated to have little influence on the added damping simulation, the standard $k-\epsilon$ model was used. Scalable wall functions were applied to near-wall regions. Three different inlet velocities, including the $100 \%$, $75 \%$, and $50 \%$ of the inlet velocity under the best efficiency of the runner, were simulated. A pressure outlet was also used with a relative pressure of $0 \mathrm{~Pa}$. To simulate the added damping of the $0 \mathrm{ND}$ mode, a Fourier Transformation Method was implemented, which allows us to use only two single blade passages to simulate the entire flow field with different ND blade motions [32, 33]. For every case, a total of 15 periods of oscillation was simulated. The mesh sensitivity was strictly checked, and the view has been shown in Figure 15. For one single blade passage, about $1.2 \mathrm{M}$ 

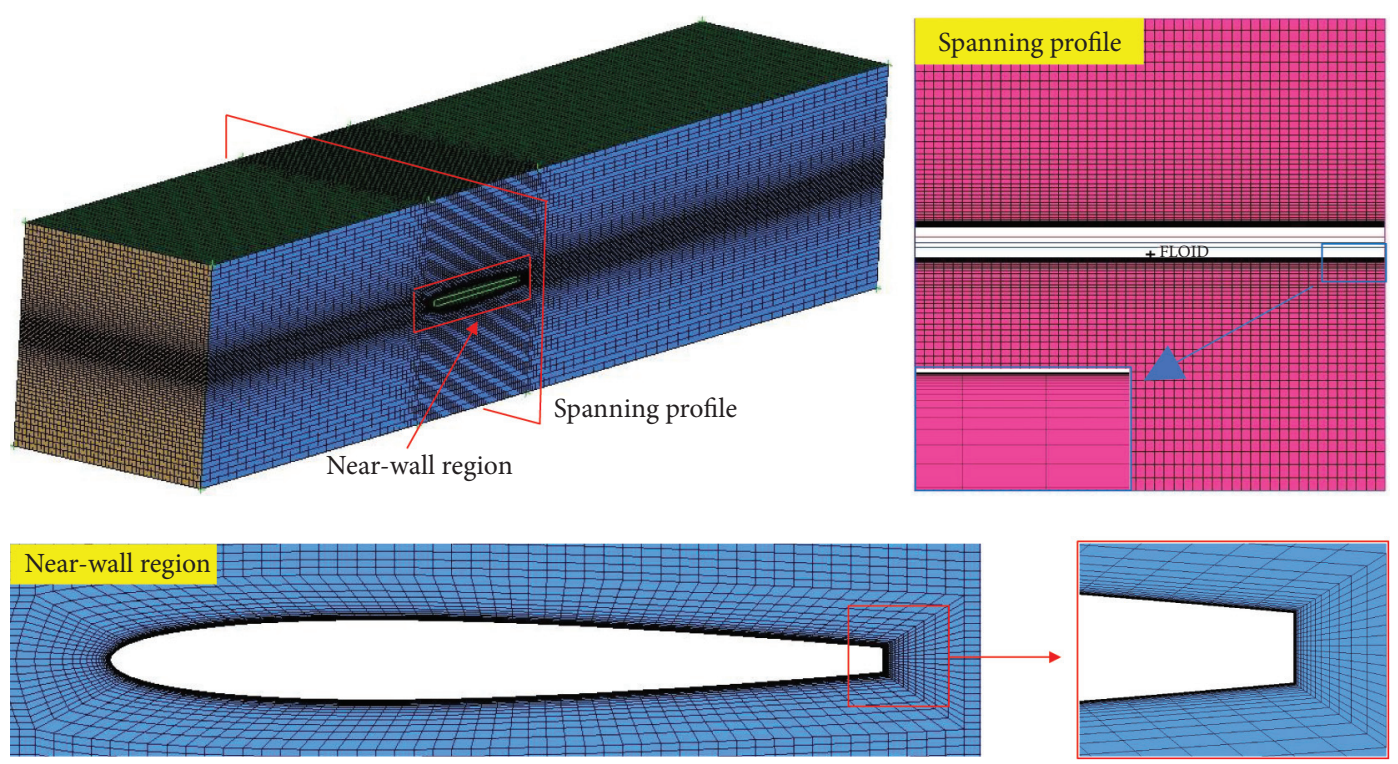

Figure 6: Surrounding domain mesh.

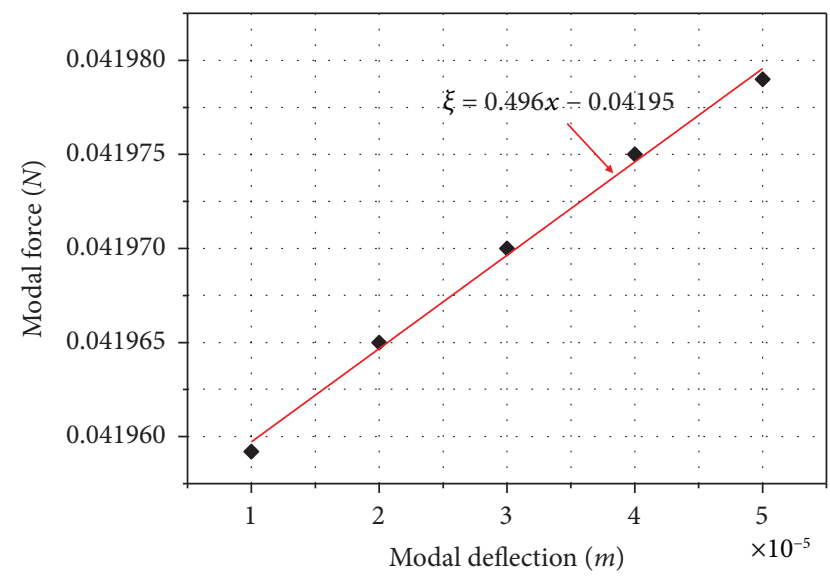

FIGURE 7: Modal force versus the modal deflection in the steady CFD analysis.

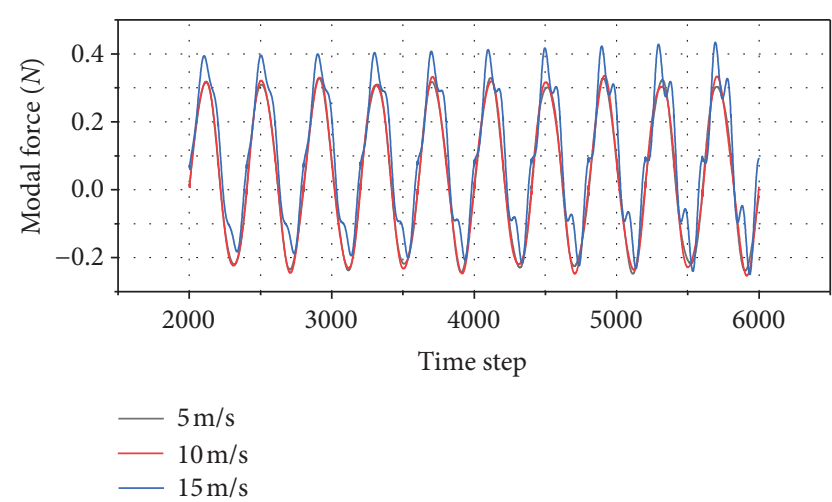

FIgURE 8: Modal forces along with the time steps under different inlet velocities.

unstructured cells were used, and boundary layers on the blade profiles were created with the $y+$ lower than 150 (the

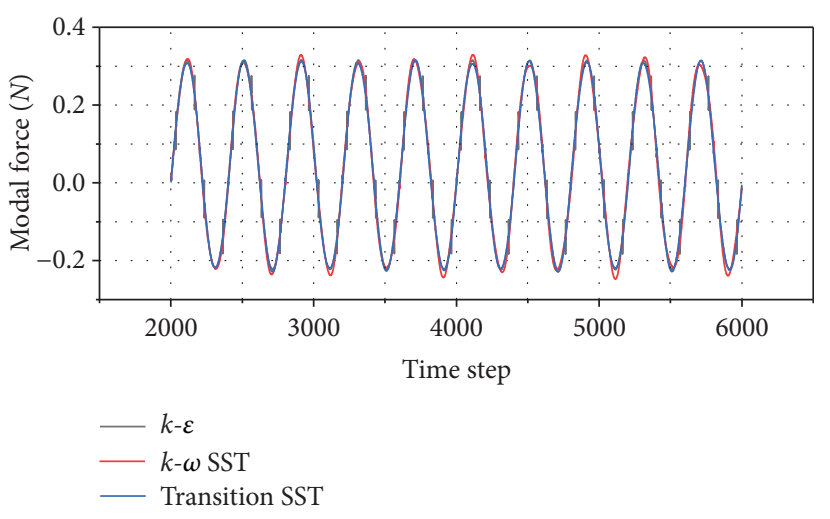

FIgURE 9: Modal forces along with the time steps under different turbulence models.

TABLE 2: Frequency interactives.

\begin{tabular}{lc}
\hline$(\mathrm{Hz})$ & Frequency interactives \\
\hline Initial frq. & 189.94 \\
Step 1 & 191.26 \\
Step 2 & 191.41 \\
\hline
\end{tabular}

The final damping ratios of the blunt and Donaldson hydrofoil under different inlet velocities have been shown in Figures 10(a) and 10(b), respectively.

thickness of the first layer is about $0.1 \mathrm{~mm}$ ). A backward Euler second-order time integration scheme was also implemented in the analysis. The time step was also selected as 400 substeps per period. The double-precision solver was also selected for calculation via the 64-core cloud computer. The same as that on the hydrofoil is also two-step natural frequency updating to get the final added damping. The damping ratios of the blunt and Donaldson Kaplan turbine runners have been shown in Figure 16. 


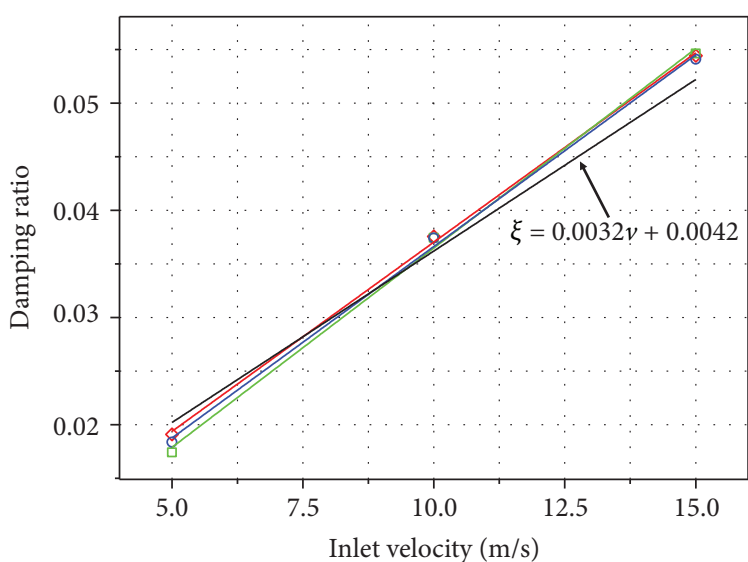

$\begin{array}{cc}\text { - One-way } k-\varepsilon & \text { One-way SST transition } \\ \text { One-way } k-\omega & \text { Two-way SST transition }\end{array}$

(a)

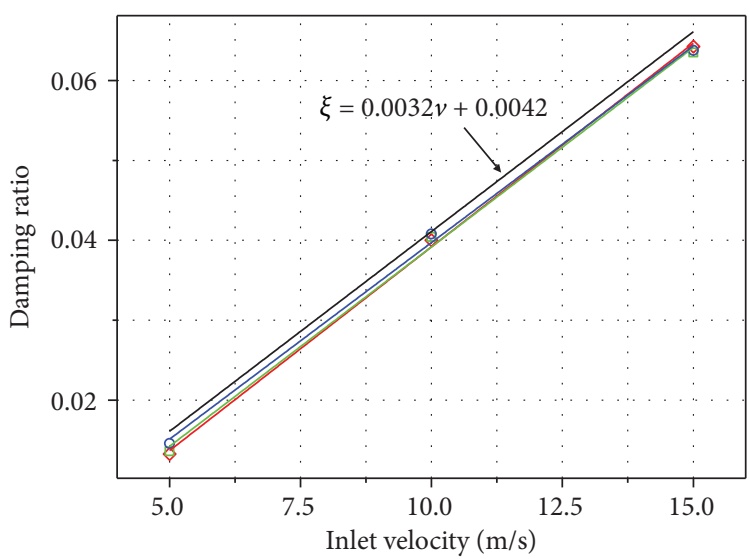

- One-way $k-\varepsilon \quad$ One-way SST transition — One-way $k-\omega \quad$ _ Two-way SST transition

(b)

FIGURE 10: Added damping ratio versus the inlet velocity. (a) Blunt hydrofoil. (b) Donaldson hydrofoil compared with the results of the twoway FSI simulation (Zeng, Y. S. et al., 2019).

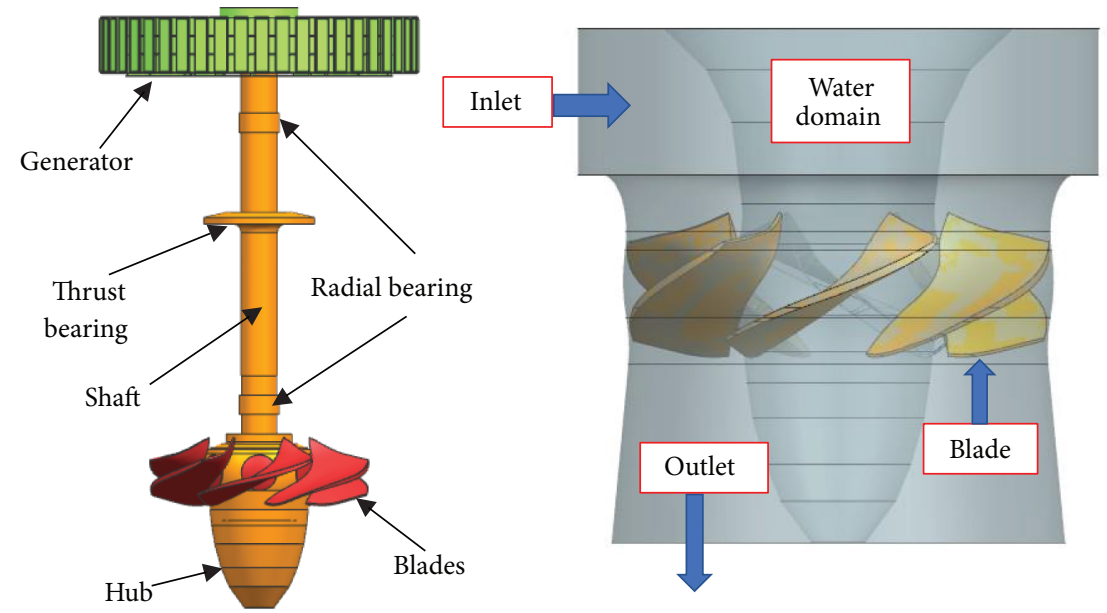

FIgURE 11: Geometry sketch of the studied Kaplan turbine.

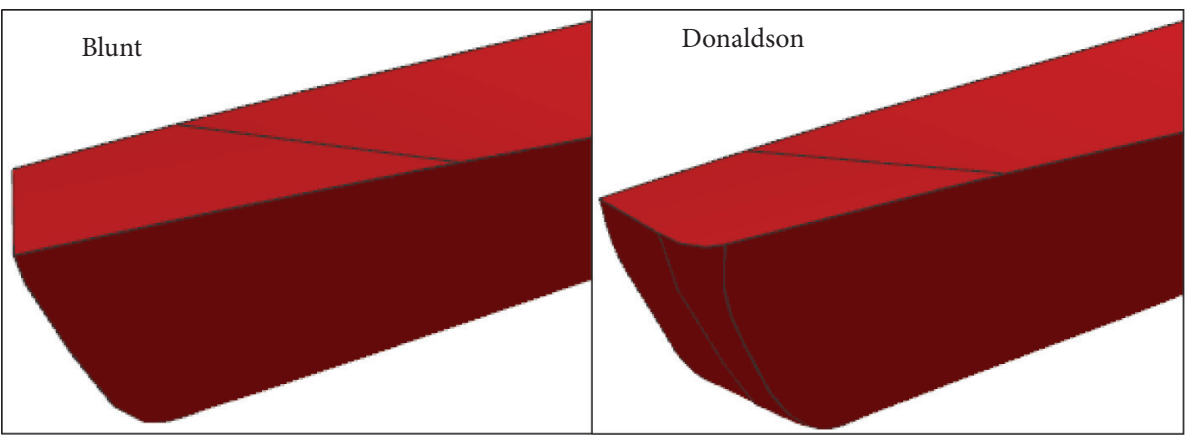

Figure 12: View of the blunt and Donaldson trailing edge of the Kaplan turbine blade. 


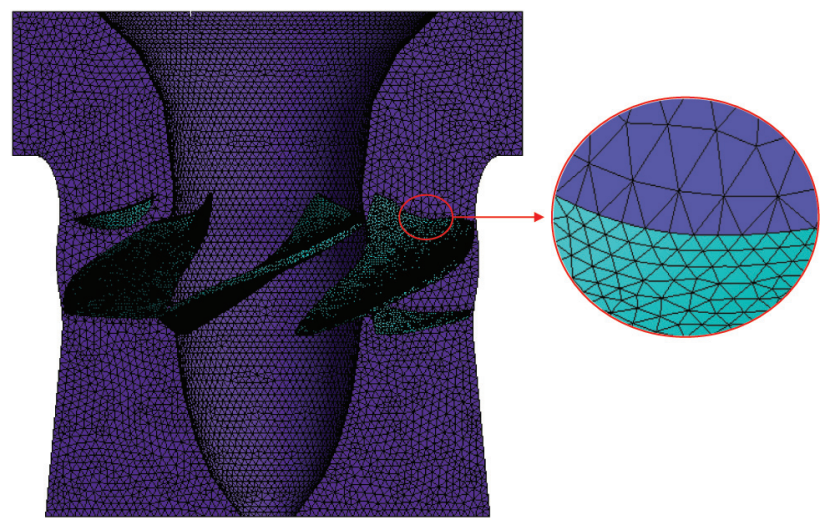

Figure 13: View of the mesh when the blades are submerged in water.

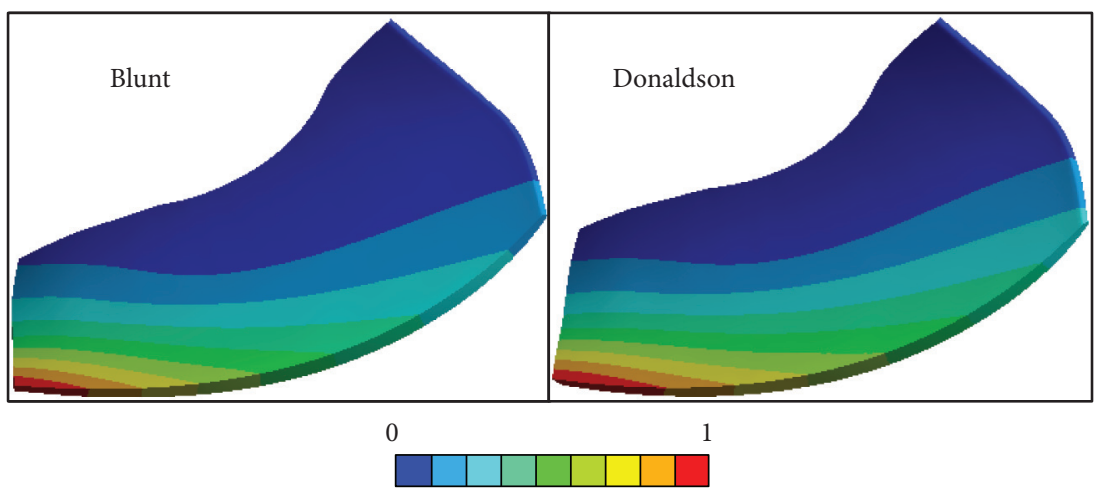

Figure 14: Bending mode shapes of the blunt and Donaldson blades.

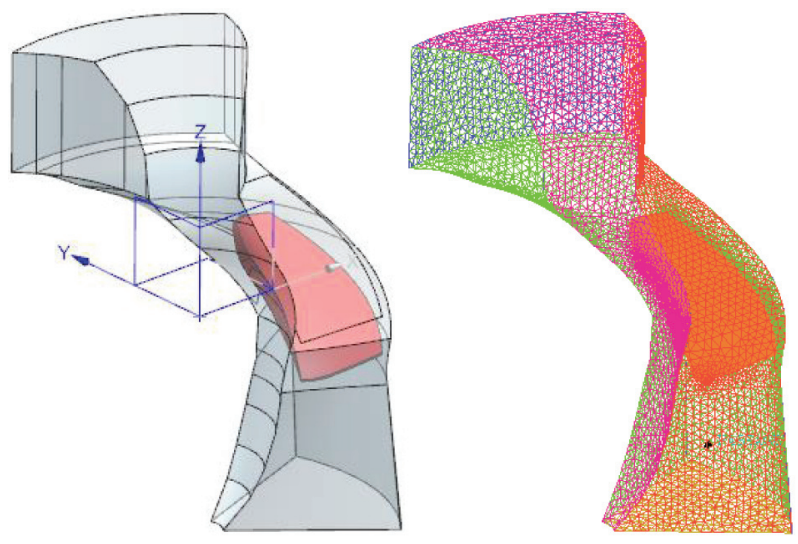

Figure 15: View of the mesh of one flow passage.

Same as the hydrofoil, the added damping linearly increases with the inlet velocity for both the blunt and Donaldson trailing edge blades, and generally, the added damping of the Donaldson trailing edge blade is higher than that of the blunt trailing edge blade when the inlet velocity is higher than some values. However, compared with the influence of the trailing edge shape on the added damping, its influence on the Kaplan turbine runner is less significant, and for each inlet velocity, the difference between two tailing edge shapes is less than $10 \%$. The reason for this may be because the Kaplan turbine blade is wider than the narrow hydrofoil, and the modal displacement concentrates more on other areas of the blade than the hydrofoil, which determines that the trailing edge shape modification produces less significant influence on the modal force than the hydrofoil, thus less significant influence on the added damping. 


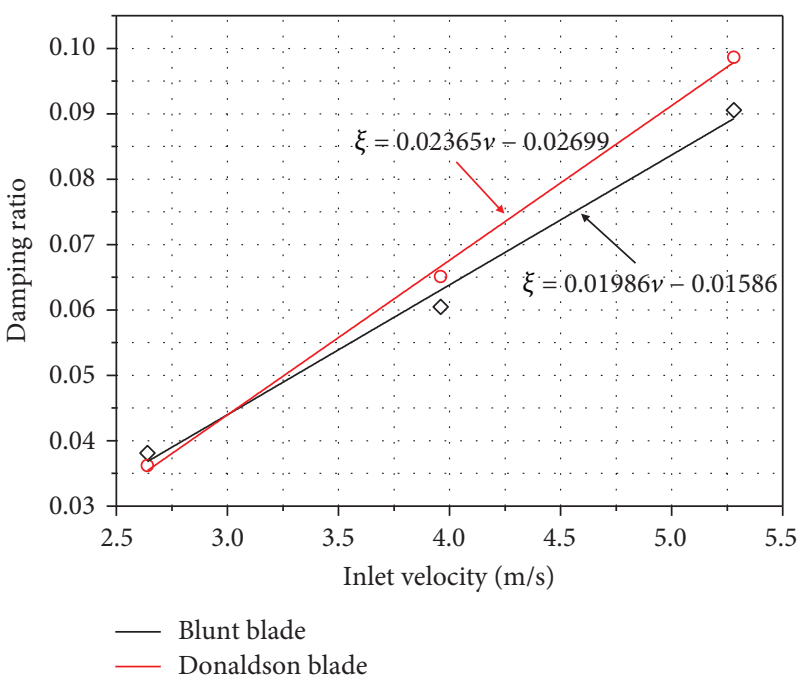

Figure 16: The damping ratios of the blunt and Donaldson Kaplan turbine runners.

\section{Conclusions}

In this paper, the influence of blade trailing edge shape on the added damping on hydraulic turbine runners has been studied. Numerical methods have been used for study in this paper. Because of the too high computation cost of the twoway fluid-structure interaction (FSI) method, the one-way FSI method was implemented. Firstly, the performances of three different turbulence models, including the $k-\epsilon, k-\omega \mathrm{SST}$, and transition SST models, in the simulation of the influence of the trailing edge shape on the added damping of hydrofoils, were evaluated by comparing with the results of the two-way FSI simulation available in the references. Unlike the turbulence model which affects the results of the two-way FSI method a lot, the performances of different turbulence models in the on-way FSI method are very close. Little errors found between the results of the three turbulence models are all very close, which provides a reference for the turbulence model chosen in the future added damping simulation using the one-way FSI method. Based on this, the $k-\epsilon$ model was applied to the added damping simulation of a Kaplan turbine runner, and the influence of the blade trailing edge shape on the added damping was investigated. Results show that the Donaldson trailing edge can increase the added damping of the Kaplan turbine runner more than the blunt trailing edge to some extent to reduce the vibration level, but the influence is less significant than that on the hydrofoil. The reason for this may be because the blades of Kaplan turbine runners are wider than the hydrofoil, which determines that the trailing edge shape modification produces less significant influence on the modal force than the hydrofoil, thus less significant influence on the added damping. In the future, the influence of the blade trailing edge shape on the added damping of other types of hydraulic turbine runners which have higher modal displacement concentrations near the blade trailing edge, like the Francis turbine runners, will be investigated to provide suggestions for the vibration level reduction.

\section{Nomenclature}

BD: Bending mode

$F_{F}$ : Total modal force

$K_{F}:$ Added stiffness

$K_{S}:$ Structural modal stiffness

$M_{S}$ : Structural modal mass

$M_{F}$ : Added mass

$n_{V}:$ Number of vertical nodal lines

TS: Torsion mode

$W$ : Modal work

$Z_{v}$ : Number of guide vanes

$\varphi$ : $\quad$ Mode shape

$\omega_{\nu}$ : Natural frequency in vacuum

$X_{0}$ : Vibration amplitude

$C_{F}:$ Added damping

FSI: Fluid-structure interaction

k: $\quad$ Flow field pressure pattern

$m_{H}$ : Number of horizontal nodal lines

ND: Nodal diameter

NL: Nodal line

RSI: Rotor-stator interaction

$\mathrm{x}: \quad$ Modal deflection

$Z_{b}$ : Number of blades

$\omega_{n}:$ Circular vibration frequency

$\xi$ : Damping ratio

$\omega_{f}:$ Natural frequency in vacuum.

\section{Data Availability}

Some or all data, models, or codes generated or used during the study are available from the corresponding author upon request.

\section{Conflicts of Interest}

The authors declare no conflicts of interest. 


\section{Acknowledgments}

The authors acknowledge the economic support received from the Natural Science Foundation of Shandong Province (no. ZR2018MEE036) and the Project of Shandong Province Higher Educational Young Innovative Talent Introduction and Cultivation Team (Performance Enhancement of Deep Coal Mining Equipment).

\section{References}

[1] 2018 Iea, Key Electricity Trends 2017 Based on Monthly Data. Monthly Electricity Statistics.

[2] G. Jacquet-Richardet, M. Torkhani, P. Cartraud et al., "Rotor to stator contacts in turbomachines. Review and application," Mechanical Systems and Signal Processing, vol. 40, no. 2, pp. 401-420, 2013.

[3] C. Nicolet, "Hydroacoustic simulation of rotor-stator interaction in resonance conditions in Francis pump-turbine," IOP Conference Series: Earth and Environmental Science, vol. 12, 2010.

[4] H. D. Li and L. He, "Blade aerodynamic damping variation with rotor-stator gap: a computational study using singlepassage approach," Journal of Turbomachinery, vol. 127, no. 3, pp. 573-579, 2005.

[5] G. A. Gerolymos, G. J. Michon, and J. Neubauer, “Analysis and application of chorochronic periodicity in turbomachinery rotor/stator interaction computations," Journal of Propulsion and Power, vol. 18, no. 6, pp. 1139-1152, 2002.

[6] X. Liu, Y. Luo, and Z. Wang, "A review on fatigue damage mechanism in hydro turbines," Renewable and Sustainable Energy Reviews, vol. 54, pp. 1-14, 2016.

[7] S. Vantadori, A. Carpinteri, and D. Scorza, "Simplified analysis of fracture behaviour of a Francis hydraulic turbine runner blade," Fatigue \& Fracture of Engineering Materials \& Structures, vol. 36, no. 7, pp. 679-688, 2013.

[8] M. Flores, G. Urquiza, and J. M. Rodríguez, "A fatigue analysis of a hydraulic Francis turbine runner," World Journal of Mechanics, vol. 2, no. 1, pp. 28-34, 2012.

[9] H. R. Krishna, Hydraulic Design of Hydraulic Machinery, Ashgate Publishing Limited, Farnham, UK, 1997.

[10] S. Liu, S. Li, and Y. Wu, "Pressure fluctuation prediction of a model Kaplan turbine by unsteady turbulent flow simulation," Journal of Fluids Engineering, vol. 131, no. 10, Article ID 101102, 2009.

[11] L. Zhou, Z. Wang, R. Xiao, and Y. Luo, "Analysis of dynamic stresses in Kaplan turbine blades," Engineering Computations, vol. 24, no. 8, pp. 753-762, 2007.

[12] K. Amiri, B. Mulu, M. Raisee, and M. J. Cervantes, "Unsteady pressure measurements on the runner of a Kaplan turbine during load acceptance and load rejection," Journal of $\mathrm{Hy}$ draulic Research, vol. 54, no. 1, pp. 56-73, 2015.

[13] R. Iovănel, D.-M. Bucur, and M. Cervantes, "Study on the accuracy of RANS modelling of the turbulent flow developed in a kaplan turbine operated at BEP. Part 1-velocity field," Journal of Applied Fluid Mechanics, vol. 12, no. 5, pp. 1449-1461, 2019.

[14] R. G. Iovanel, G. Dunca, and M. Cervantes, "Study on the accuracy of RANS modelling of the turbulent flow developed in a kaplan turbine operated at BEP. Part 2-pressure fluctuations," Journal of Applied Fluid Mechanics, vol. 12, no. 5, pp. 1463-1473, 2019.

[15] T. Rus, M. Dular, B. Širok, M. Hočevar, and I. Kern, “An investigation of the relationship between acoustic emission, vibration, noise, and cavitation structures on a kaplan turbine," Journal of Fluids Engineering, vol. 129, no. 9, pp. 1112-1122, 2007.

[16] Y. Luo, Z. Wang, J. Zeng, and J. Lin, "Fatigue of piston rod caused by unsteady, unbalanced, unsynchronized blade torques in a Kaplan turbine," Engineering Failure Analysis, vol. 17, no. 1, pp. 192-199, 2010.

[17] C. V. Frunzaverde and D. Nedelcu, "Failure analysis of a Kaplan turbine runner blade by metallographic and numerical methods," in Proceedings of the 7th WSEAS International Conference on Fluid Mechanics (Fluids'10), Cambridge, UK, January 2010.

[18] G. Urquiza, J. C. García, J. G. González et al., "Failure analysis of a hydraulic Kaplan turbine shaft," Engineering Failure Analysis, vol. 41, pp. 108-117, 2014.

[19] B. Nennemann, C. Monette, and J. Chamberland-Lauzon, "Hydrodynamic damping and stiffness prediction in Francis turbine runners using CFD," IOP Conference Series: Earth and Environmental Science, vol. 49, 2016.

[20] C. Trivedi, "A review on fluid structure interaction in hydraulic turbines: a focus on hydrodynamic damping," Engineering Failure Analysis, vol. 77, pp. 1-22, 2017.

[21] L. Lu, Y. R. Yang, P. Li, and M. L. Zhang, "Added mass, added stiffness and added damping coefficients for a parallel platetype structure," Applied Mechanics and Materials, vol. 66-68, pp. 1738-1742, 2011.

[22] W. K. Blake, "Introductory concepts," Applied Mathematics and Mechanics, pp. 1-43, 1986.

[23] A. Zobeiri, "Effect of hydrofoil trailing edge geometry on the wake dynamics," Ph.D. thesis, EPFL, Lausanne, Switzerland, 2012.

[24] Z. Yao, F. Wang, M. Dreyer, and M. Farhat, "Effect of trailing edge shape on hydrodynamic damping for a hydrofoil," Journal of Fluids and Structures, vol. 51, pp. 189-198, 2014.

[25] Y. S. Zeng, Z. F. Yao, P. J. Zhou, F. J. Wang, and Y. P. Hong, "Numerical investigation into the effect of the trailing edge shape on added mass and hydrodynamic damping for a hydrofoil," Journal of Fluids and Structures, vol. 88, pp. 167-184, 2019.

[26] Y. Zeng, "Numerical investigation of added mass and hydrodynamic damping on a blunt trailing edge hydrofoil," Journal of Fluids Engineering, vol. 141, no. 8, 2019.

[27] E. Tengs, "Numerical simulation of the hydrodynamic damping of a vibrating hydrofoil," IOP Conference Series: Earth and Environmental Science, vol. 240, 2019.

[28] J. P. Gauthier, A. M. Giroux, S. Etienne, and F. P. Gosselin, “A numerical method for the determination of flow-induced damping in hydroelectric turbines," Journal of Fluids and Structures, vol. 69, pp. 341-354, 2017.

[29] X. Liu, "Numerical simulation of added mass effects on a hydrofoil in cavitating flow using acoustic fluid-structure interaction," Journal of Fluids Engineering, vol. 139, no. 4, 2017.

[30] M. Zhang, On the Changes in Dynamic Behavior Produced by the Hydraulic Turbine Runner Damage, 2019.

[31] M. Zhang, "Influence of internal blade-interactions on the added mass and added damping of a prototype Kaplan turbine runner," Alexandria Engineering Journal, 2021, In Press.

[32] S. Connell, M. Braaten, L. Zori, R. Steed, B. Hutchinson, and G. Cox, "A comparison of advanced numerical techniques to model transient flow in turbomachinery blade rows," Turbo Expo: Power for Land, Sea and Air, pp. 1241-1250, 2011.

[33] S. Gautam, "Numerical investigation of the effects of leakage flow from guide vanes of Francis turbines using alternative clearance gap method," Journal of Applied Fluid Mechanics, vol. 13, no. 5, pp. 1407-1419, 2020. 